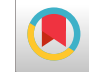

\title{
Knowledge, Attitude, and Practice (KAP) Towards COVID-19 Among General Population of South Khorasan Province, Iran: A Quick Online Cross-sectional Survey
}

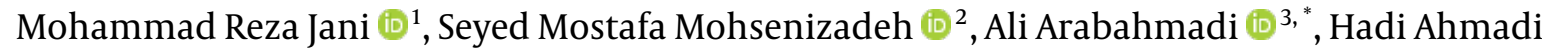 \\ Chenari (iD ${ }^{1}$ and AmirHossin Rajabi (iD ${ }^{4}$ \\ ${ }^{1}$ Department of Nursing, Ferdows School of Paramedical and Health, Birjand University of Medical Sciences, Birjand, Iran \\ ${ }^{2}$ Department of Nursing, Qaen School of Nursing and Midwifery, Birjand University of Medical Sciences, Birjand, Iran \\ ${ }^{3}$ Department of Public Health, Qaen School of Nursing and Midwifery, Birjand University of Medical Sciences, Birjand, Iran \\ ${ }^{4}$ Department of Nursing, Medical Faculty, Hamedan Branch, Islamic Azad University, Hamedan, Iran \\ "Corresponding author: Department of Public Health, Qaen School of Nursing and Midwifery, Birjand University of Medical Sciences, Birjand, Iran. Email: \\ aliarabahmadi69@gmail.com
}

Received 2021 November 02; Revised 2021 December 04; Accepted 2021 December 18.

\begin{abstract}
Background: COVID-19 is a highly contagious disease and a pandemic. Knowledge, attitude, and practice of people about this disease can play an essential role in better accepting executive actions set by health officials and national planners.

Objectives: This study aimed to determine the level of knowledge, attitude, and practice of the general population of South Khorasan province about COVID-19 and the influencing factors.

Methods: This cross-sectional study was performed online on 699 people living in South Khorasan, Iran. The participants were chosen by a convenience sampling technique. The research tool was an adapted questionnaire from researchers that included demographic characteristics, 15 questions on awareness, 12 questions on attitude, and seven questions on practice. Data were analyzed using the independent $t$ test, one-way analysis of variance, and Pearson correlation coefficient.

Results: The levels of knowledge, attitude, and practice of the participants were $73.13,80$, and $84.85 \%$, respectively. The most common symptoms of this disease were shortness of breath, dry cough, and fever or headache, in sequence. More than half of the participants (56.90\%) felt at risk for contracting the disease. Most participants washed their hands (80\%) and used a facemask (79.60\%). The correlation between awareness and practice was 0.60 . Older, divorced, and low-educated people had lower knowledge and practice. Conclusions: Despite that the levels of knowledge, attitude, and practice of people was good regarding COVID-19 in this study, the continuous informing of the people through television, radio, and social media is needed for maintaining the status quo. Besides, new approaches and policies for the poor, rural populations, the elderly, the illiterate, and the unemployed should be adopted by relevant authorities due to their lower level of knowledge and practice.
\end{abstract}

Keywords: COVID-19, Knowledge, Attitude, Practice, South Khorasan, Pandemic

\section{Background}

Coronaviruses are a subspecies of Coronaviridae and are a large family of viruses that can cause a wide range of illnesses, from the common cold to more severe illnesses such as MERS, SARS, and COVID-19 (1). COVID-19 was first discovered in late December in Wuhan, China (2). As it had a high rate of spreading, it soon reached other cities in China and then all parts of the world (3), so that it was declared a pandemic by the World Health Organization (4). It has affected many countries globally, and the number of confirmed cases and deaths has increased increasingly (5). On February 20, 2020, the first confirmed case of COVID-19 was found in Iran in Qom (6). In Iran, as in other countries of the world, the number of cases and deaths has increased (5).

About $81 \%$ of COVID-19 patients have a mild illness, and only $14 \%$ of cases have a severe form, while $5 \%$ experience the critical phase of the disease. However, the fatality rate of this disease is higher in older people with underlying conditions (7). The disease is associated with symptoms such as cough, fever, fatigue, sore throat, pneumonia, diarrhea, headache, and shortness of breath (8) and can be transmitted by coughing and sneezing in close contact (approximately one meter) and contact with equipment and objects the infected person has touched $(9,10)$. Currently,

Copyright (C) 2022, Modern Care Journal. This is an open-access article distributed under the terms of the Creative Commons Attribution-NonCommercial 4.0 International License (http://creativecommons.org/licenses/by-nc/4.0/) which permits copy and redistribute the material just in noncommercial usages, provided the original work is properly cited. 
there is no officially approved antiviral treatment (11), so one of the most important ways to prevent this disease is to use personal protective equipment (such as a facemask), frequent handwashing when leaving the house, not to have close contact with suspected or positive COVID-19 cases, and not traveling to high-risk areas (12).

Knowledge, attitude, and practice (KAP) studies are one of the most widely used studies in the field of healthrelated behaviors in the population (13) and are used as an essential tool to control and prevent epidemics (14). Such studies show the extent to which people in the community are concerned about the issues related to their health (15). On the other hand, preventive interventions in a population effectively control the disease when the difference between the knowledge, attitude, and practice of people about a disease is known before the implementation of interventions (16). Given the experiences and evidence of epidemics of Ebola, Middle East Respiratory Syndrome (MERS), and Severe Acute Respiratory Syndrome (SARS) (1720), the awareness, attitude, and understanding of the risks of an epidemic can play an essential role in controlling the disease. Thus, evaluating individuals' knowledge, attitude, and practice is very necessary as it can prevent the transmission of the disease and help control it. It also influences people's behaviors and provides a basis for behavioral change according to national and international guidelines.

People of Iran have already experienced four waves of coronavirus disease, and in the meantime, they have received much information about this disease from the media, the Health Ministry, and health centers. Therefore, the question is that after 18 months since the onset of COVID19 in Iran, are the people's awareness, attitude, and preventive measures of this disease at a desirable level?

\section{Objectives}

The purpose of this study was to determine the level of knowledge, attitude, and practice taken by the general population of South Khorasan province about the COVID19 pandemic and the influencing factors.

\section{Methods}

\subsection{Study Design and Population}

This online cross-sectional study was conducted in eastern Iran on the general population of South Khorasan province, with the capital Birjand. To collect data, we designed an online questionnaire with questions on demographics including age, sex, marital status, education level, occupation, residence place, income, and residence area in
South Khorasan. There were also questions on knowledge, attitude, and practice derived from the instructions of the Ministry of Health of the Islamic Republic of Iran, WHO, and KAPs of previous epidemics (MERS and SARS). Also, a question about the source of information about COVID-19 was added to the questionnaire $(18,20-22)$.

Experts in the field, including 10 public health and epidemiology experts, were then asked to review the tool and provide feedback on the simplicity and comprehensibility of the questions relevant to the target population and their relevance to COVID-19. According to the Lawshe table, the minimum CVR value for each question should be 0.62 , which was higher for all questions in our study. Also, according to the Waltz and Basel method, the minimum acceptable value for the CVI index for each question should be 0.79 , which was higher for all questions in the pretest of our study. Also, S-CVI/Ave was calculated to be equal to 0.93. Then, a pilot study was conducted on 18 citizens two weeks before and after the test. The reliability value based on Kuder-Richardson for the questionnaire was 0.81 , and the intra-cluster correlation in terms of knowledge, attitude, and practice was estimated to be 80,76 , and $71 \%$, respectively.

\subsection{Instruments}

This questionnaire included 34 questions. There were 15 questions on the knowledge, including items 1 to 15 (score range from 0 to 15), 12 questions on attitude and risk perception of the disease including items 16 to 27 (score range from 0 to 12), and seven functional questions on taking precautions to prevent the disease including items 28 to 34 (score range from 0 to 7). The options were "correct," "wrong," and "I am not sure". People got one score for a correct answer to each question and zero scores for wrong or unsure answers. In general, the higher the scores of people in these areas, the higher their knowledge, attitude, and practice.

\subsection{Procedure}

The questionnaire was designed electronically, and its link (www.cafepardazesh.ir) was distributed on social media through Telegram and WhatsApp in South Khorasan province in several stages. Questionnaires completed earlier than one minute or later than one hour were excluded from the study. The participants were chosen by a convenience sampling technique.

\subsection{Statistical Analyses}

Data analysis was performed using SPSS version 24 (IBM Corp., Armonk, NY, USA) at a 5\% error level. Descriptive statistics such as frequencies, percentages, means, and 
standard deviation were used to summarise qualitative data. As the data were normal, an independent $t$-test, oneway analysis of variance, and Pearson correlation coefficient were used.

\subsection{Ethics Statement}

This initiative complied with ethical standards set by Birjand University of Medical Sciences and the Declaration of Helsinki. Also, this research was approved by the Ethics Committee of Birjand University of Medical Sciences with the ethics code of IR.BUMS.REC.1399.023. Informed consent was obtained from all individual participants included in the study.

\section{Results}

A total of 699 participants completed the survey questionnaire. The mean age of the participants was $28.90 \pm$ 9.58 years. Among the participants, $61.51 \%$ were females, and $38.49 \%$ were males. Besides, $89.2 \%$ of participants were from urban areas (Table 1 ).

According to the results of the study, participants received their information about COVID-19 often from TV (490 people, $71 \%$ ) and social media such as Telegram, WhatsApp, Instagram, etc. (447 people, 64.8\%) (Figure 1).

The mean knowledge score of the subjects was 21.94 \pm 4.05 out of a maximum score of 30 . Besides, $97.20 \%$ of people were aware that COVID-19 was contagious. Also, most participants (98.30\%) agreed that people suspected of the disease should be isolated from other people in the community. The majority of people were well aware of the disease transmission ways, and only $1.30 \%$ said they were unaware. Also, the most common symptoms of this disease were shortness of breath, dry cough, and fever or headache, in sequence (Table 2). The mean score for the subjects' attitudes was $9.61 \pm 1.81$ out of a maximum score of 12 . Besides, $87.20 \%$ of the participants considered COVID19 dangerous, and more than half (56.90\%) felt at risk of contracting the disease. Accordingly, most people (81.70\%) mentioned getting the vaccine if it was available (Table 3 ). The mean scores of the subjects' practice were $5.94 \pm 1.76$ out of a maximum score of 7 . Also, $94.80 \%$ of the participants stated that washing their hands with soap and water frequently was one of their actions, and $86.80 \%$ preferred to stay at home to cut the disease's transmission chain (Table 3).

The results showed a significant relationship between the average level of knowledge, attitude, and practice of individuals and variables such as age, marital status, education level, occupation, and income $(\mathrm{P}<0.05)$ (Table 4).

Regarding the relationship between the main variables of the study, Pearson correlation coefficient showed a significant positive relationship between knowledge and attitude $(\mathrm{r}=0.33$, P-value $<0.001)$, knowledge and practice $(\mathrm{r}=0.60$, P-value $<0.001)$, and attitude and practice $(\mathrm{r}=$ 0.25 , P-value $<0.001$ ).

\section{Discussion}

This study aimed to determine the level of knowledge, attitude, and practice in the general population of South Khorasan province about the COVID-19 pandemic and its influencing factors. In the present study, the people's knowledge in South Khorasan province, Iran, about COVID19 was moderate $(21.94 \pm 4.05$ out of a maximum score of 30), indicating a $73.13 \%$ knowledge and awareness level.

Middle-aged people showed a higher level of knowledge than other age groups, possibly because this age group follows information and news more. In a study conducted by Abdelhafiz et al. in Egypt, the level of awareness of individuals was reported to be $74.50 \%$ (23), which is similar to the present study. In studies from other countries, a percentage between 63 and 99.50\% was reported (6, 24-27). These differences can be due to different measurement tools, sample sizes, cultures, and study time in different countries. The primary source of information about COVID-19 was the national television (490 people, 71\%) and social media such as Telegram, WhatsApp, Instagram, etc. (447 people, 64.8\%). Apart from a similar study conducted by Honarvar et al. in Iran (6), numerous other studies have cited social media as the primary source of information for individuals $(23,26-29)$. In recent years, due to the advancement of technology and the ease of access to the Internet, the desire of people to use social media has increased (6), but according to specific rules in Iran, many social media apps are filtered, and not all the people have easy access to them.

In addition, $85.50 \%$ of the people in the present study considered COVID-19 a virus, and over $97 \%$ of them agreed that the disease was contagious and people suspected of the disease should be isolated from the rest of the community. The incubation period, transmission routes, and symptoms of COVID-19 were also well known to the participants. These findings are consistent with Reuben et al.'s (26) and Lau et al.'s (30) studies. These studies also assessed knowledge about the incubation period, transmission routes, and symptoms of COVID-19 at a reasonable level (above 86 and 89.50\%, respectively). However, in the study conducted on Indians, people's knowledge about this disease was deficient, so that this rate was between 7.7 and $18.2 \%$ for the main symptoms of the disease, such as fever, cough, shortness of breath, etc. Also, 29.5\% of people considered touching, kissing, sneezing, and eating as the 


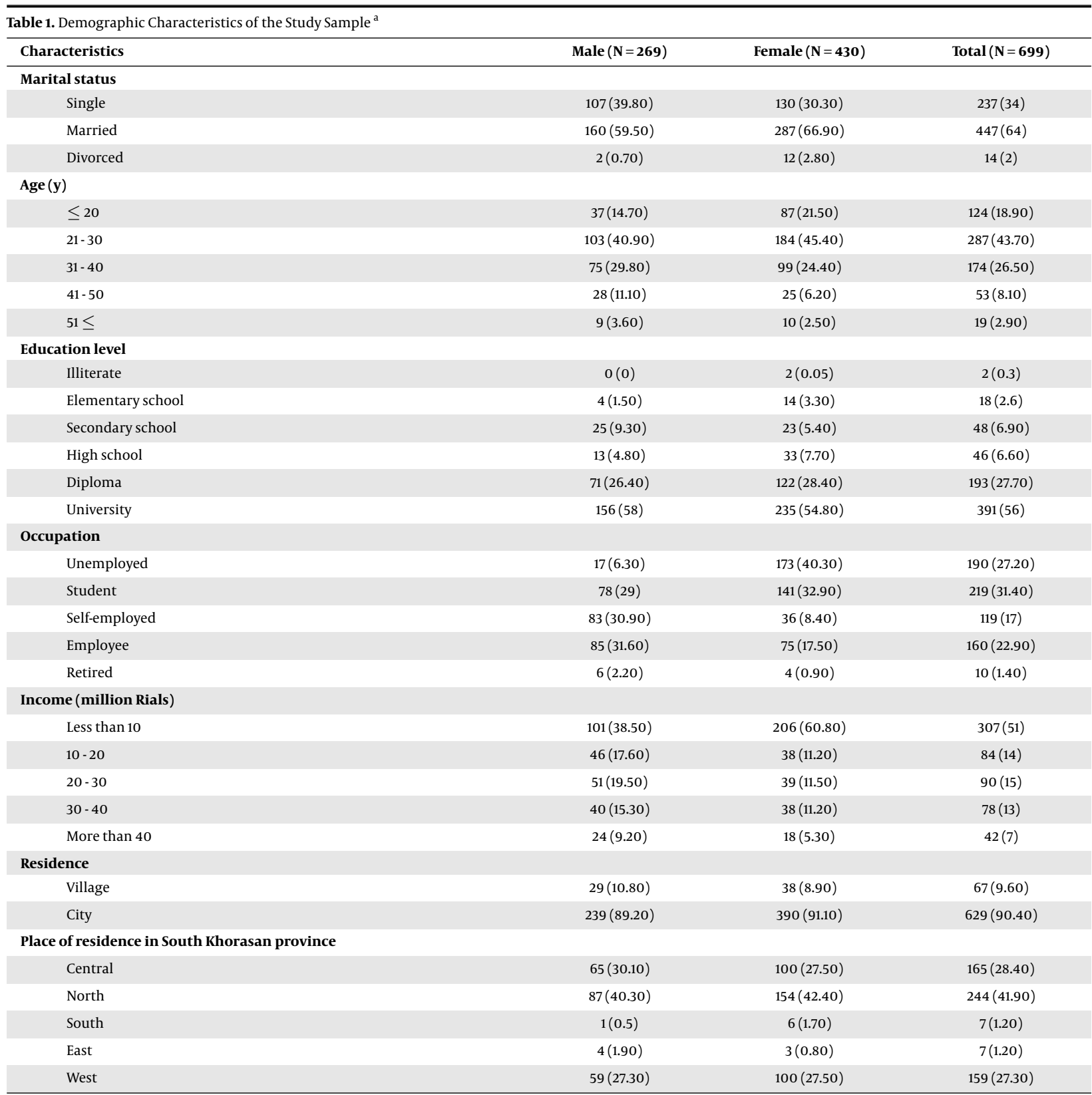

${ }^{a}$ Values are expressed as No. (\%).

ways of transmitting the disease, and 57\% did not consider this disease contagious (31).

The attitudes of individuals can play an essential role in controlling diseases; in fact, they are a bridge between awareness and practice that can make the connection between the two easier, ultimately leading to behavior change (32). Most people in the study had a high understanding of the risk of transmitting the disease, and up to $85 \%$ were worried about having a family member with the disease. Besides, almost a little over half of the people felt at risk. It is in line with the study of Honarvar et al. in Shiraz, Iran. In this study, like our study, almost half of the people felt threatened by this disease, and most of them were worried about their families contracting the disease (6). According to a study by Huynh et al. in medical staff, almost $80 \%$ of people were worried about themselves and their families contracting the disease (11). Also, 86\% of Egyptians considered this disease dangerous, and 


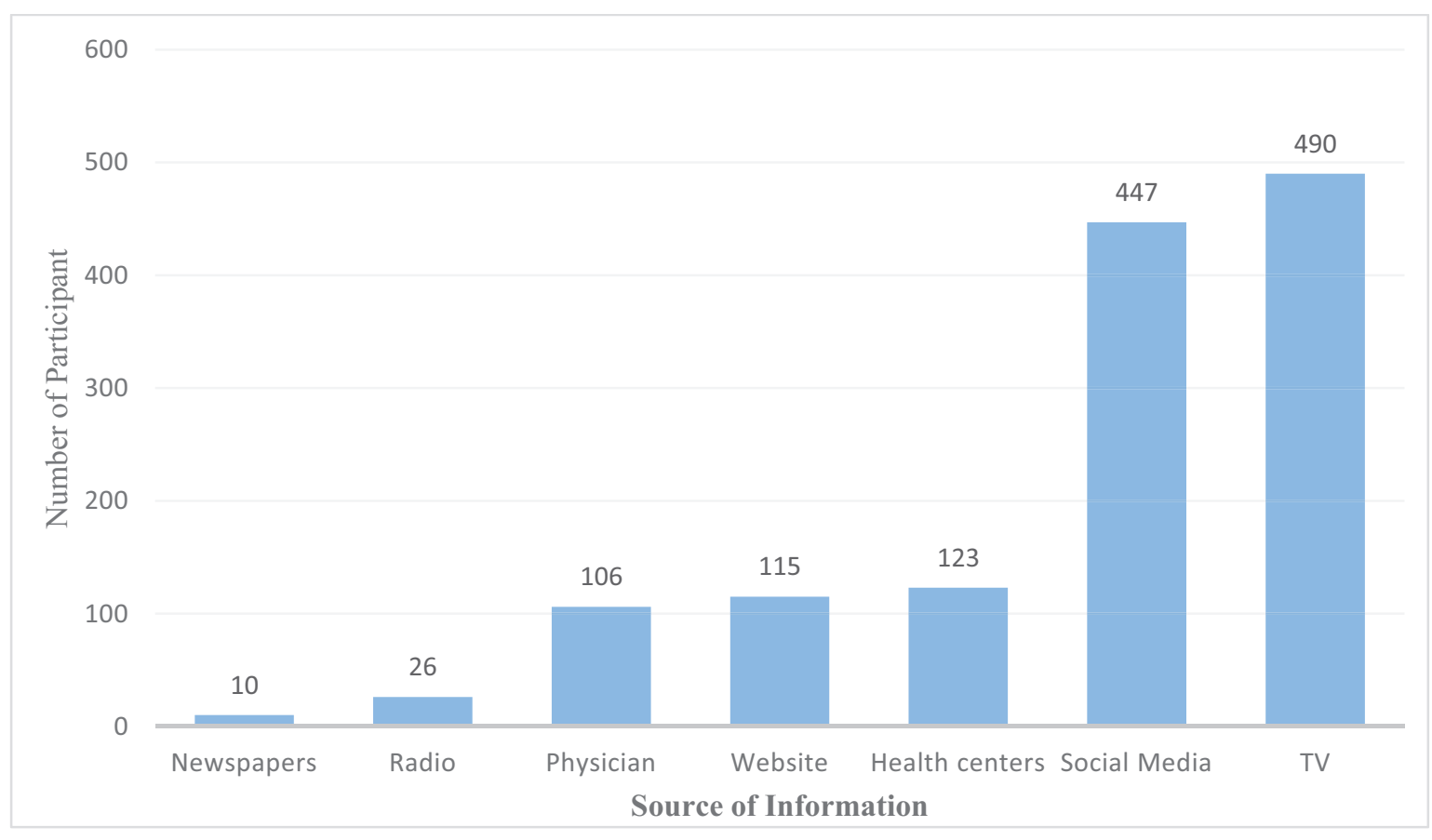

Figure 1. Reported sources of knowledge about COVID-19

$86.9 \%$ worried that they or their families would be infected (23). The discrepancy between Iranian studies and other worldwide studies concerning the lack of deep concern of people about the risk of disease in Iran can be due to that in the present study, most of the participants were young and believed that the disease could be dangerous only for the elderly and those with underlying diseases, which has already been confirmed in some studies $(33,34)$. Also, the role of Iranian media in making this disease seem less important for young people and individuals without underlying diseases in the early days of the epidemic has created this belief in people, especially adolescents and young people, that this disease cannot be too dangerous for them.

Most people (81.70\%) mentioned that they would get the COVID-19 vaccine if there was one available, while the Nigerians had little faith in this, and only $29 \%$ of them would get vaccinated. According to the author, this could be due to the fear and misconceptions created by the media about the health risks of these vaccines (26).

A total of $84.85 \%$ of participants took measures to prevent the COVID-19 disease. Of them, $94.80 \%$ washed their hands, and more than $76 \%$ of them used facemasks and threw them in the trash after use. These rates on the use of facemasks and handwashing are higher than those of Honarvar et al. and Azlan studies so that the desire of peo- ple to use masks was approximately $60 \%$ and $50 \%$ and the desire to wash hands was 80 and $87 \%$ in these two studies, respectively $(6,24)$.

The results showed a significant positive relationship between knowledge and attitude, knowledge and practice, and attitude and practice, which is consistent with the results of other studies $(6,26,29)$. Therefore, increasing knowledge and changing attitudes can change people's behavior positively (33).

Our findings also showed a significant relationship between age and education level of individuals and their practice in the prevention of COVID-19, which is consistent with the results of studies conducted by Honarvar et al. (6), Lau et al. (30), and Zhong et al. (27). Age and education level are two factors that make a person experience over time; in fact, with their increase, a person's experience also increases, strengthening the person's performance in critical situations.

\subsection{Study Limitations}

Due to the electronic implementation of the present study, limited access to telephones and the Internet in the villages, and the low level of literacy of rural people, the number of rural participants in this study was low. As the Iran health system is coherent and readily available 


\begin{tabular}{|c|c|c|c|c|c|c|}
\hline Variables & Knowledge & $\mathbf{P}$ & Attitude & $\mathbf{P}$ & Practice & $\mathbf{P}$ \\
\hline Gender & & 0.18 & & 0.36 & & 0.35 \\
\hline Male & $21.71 \pm 4.23$ & & $9.70 \pm 1.93$ & & $5.88 \pm 1.81$ & \\
\hline Female & $22.13 \pm 3.89$ & & $9.57 \pm 1.74$ & & $6.01 \pm 1.72$ & \\
\hline $\operatorname{Age}(y)$ & & 0.11 & & 0.028 & & 0.001 \\
\hline$\leq 20$ & $21.37 \pm 4.01$ & & $9.18 \pm 2.01$ & & $5.42 \pm 1.95$ & \\
\hline $21-30$ & $22.19 \pm 3.72$ & & $9.69 \pm 1.65$ & & $6.08 \pm 1.53$ & \\
\hline $31-40$ & $22.25 \pm 4.17$ & & $9.77 \pm 1.63$ & & $6.09 \pm 1.81$ & \\
\hline $41-50$ & $22.77 \pm 3.19$ & & $9.88 \pm 1.53$ & & $6.37 \pm 1.41$ & \\
\hline $51 \leq$ & $21.10 \pm 5.13$ & & $9.42 \pm 2.56$ & & $5.68 \pm 2.26$ & \\
\hline Marital status & & 0.002 & & $<0.001$ & & 0.004 \\
\hline Single & $21.67 \pm 3.91$ & & $9.29 \pm 2.08$ & & $5.77 \pm 1.81$ & \\
\hline Married & $22.23 \pm 3.96$ & & $9.82 \pm 1.60$ & & $6.09 \pm 1.68$ & \\
\hline Divorced & $18.61 \pm 6.27$ & & $8.53 \pm 2.29$ & & $4.76 \pm 2.45$ & \\
\hline Residence & & 0.062 & & 0.81 & & 0.050 \\
\hline Village & $20.85 \pm 4.99$ & & $9.57 \pm 2.05$ & & $5.46 \pm 2.16$ & \\
\hline City & $22.08 \pm 3.91$ & & $9.63 \pm 1.78$ & & $6.02 \pm 1.70$ & \\
\hline Education level & & $<0.001$ & & 0.033 & & 0.009 \\
\hline Less than a diploma & $19.92 \pm 4.96$ & & $9.21 \pm 2.23$ & & $5.46 \pm 2.23$ & \\
\hline Diploma and above & $22.36 \pm 3.70$ & & $9.70 \pm 1.71$ & & $6.05 \pm 1.63$ & \\
\hline Occupation & & 0.001 & & 0.002 & & 0.030 \\
\hline Unemployed & $21.39 \pm 4.54$ & & $9.45 \pm 1.76$ & & $5.96 \pm 1.88$ & \\
\hline Student & $21.74 \pm 3.84$ & & $9.34 \pm 1.96$ & & $5.70 \pm 1.77$ & \\
\hline Self-employed & $21.66 \pm 3.94$ & & $9.83 \pm 1.84$ & & $5.93 \pm 1.84$ & \\
\hline Employee & $23.12 \pm 3.50$ & & $10.05 \pm 1.56$ & & $6.30 \pm 1.46$ & \\
\hline Retired & $23.00 \pm 3.46$ & & $9.50 \pm 1.64$ & & $6.10 \pm 1.52$ & \\
\hline Income (million Rials) & & 0.003 & & 0.070 & & 0.054 \\
\hline Less than 10 & $21.66 \pm 4.23$ & & $9.52 \pm 1.82$ & & $5.84 \pm 1.76$ & \\
\hline $10-20$ & $21.59 \pm 3.97$ & & $9.76 \pm 1.61$ & & $6.05 \pm 1.75$ & \\
\hline $20-30$ & $22.15 \pm 4.35$ & & $9.91 \pm 1.83$ & & $5.95 \pm 1.91$ & \\
\hline $30-40$ & $23.55 \pm 3.22$ & & $10.06 \pm 1.55$ & & $6.44 \pm 1.18$ & \\
\hline Above 40 & $22.90 \pm 3.32$ & & $9.97 \pm 1.55$ & & $6.33 \pm 1.35$ & \\
\hline
\end{tabular}

${ }^{\text {a }}$ Values are expressed as mean $\pm \mathrm{SD}$.

for people in rural health centers and homes, it is suggested that future studies be conducted on these people and their information be collected in person. In addition, the chances of weak and vulnerable people, including the elderly, the illiterate, and the unemployed, were low to participate in the study, which certainly affected the KAP score. Also, as electronic questionnaires were used, random sampling was not possible. Besides, many people could not participate in the study due to the filtering of social me- dia applications such as Telegram in Iran. However, in this study, we tried to use other social media apps that were readily available, such as WhatsApp, to solve this problem.

\subsection{Conclusions}

Despite that the level of knowledge, attitude, and practice of people was good regarding COVID-19 in this study, the continuous informing of the people through television, radio, and social media is needed for maintaining 
the status quo. Besides, new approaches and policies for the poor, rural populations, the elderly, the illiterate, and the unemployed should be adopted by relevant authorities due to their lower level of knowledge and practice.

\section{Acknowledgments}

I wish to extend my special thanks to Birjand University of Medical Sciences and all respondents who participated in the research.

\section{Footnotes}

Authors' Contribution: Study concept and design, A.A, SM.M, AH.R, and MR.J; Analysis and interpretation of data, A.A and H.ACh; Drafting of the manuscript, MR.J, AH.R, and SM.M; Critical revision of the manuscript for important intellectual content, A.A, H.ACh, and MR.J; Statistical analysis, A.A.

Conflict of Interests: The authors have no conflicts of interest associated with the material presented in this paper.

Data Reproducibility: The data presented in this study are openly available in one of the repositories or will be available on request from the corresponding author by this journal representative at any time during submission or after publication. Otherwise, all consequences of possible withdrawal or future retraction will be with the corresponding author.

Ethical Approval: This study was approved by the Ethics Committee of Birjand University of Medical Sciences (code: IR.BUMS.REC.1399.023)

Funding/Support: This study received no funding.

Informed Consent: Informed consent was obtained from all participants included in the study.

\section{References}

1. National Institute of Allergy and Infectious Diseases. Coronaviruses Maryland, USA: National Institute of Allergy and Infectious Diseases; 2021, [cited 2021]. Available from: https://www.niaid.nih.gov/ diseases-conditions/coronaviruses.

2. Holshue ML, DeBolt C, Lindquist S, Lofy $\mathrm{KH}$, Wiesman J, Bruce $\mathrm{H}$, et al. First Case of 2019 Novel Coronavirus in the United States. N Engl J Med. 2020;382(10):929-36. doi: 10.1056/NEJMoa2001191. [PubMed: 32004427]. [PubMed Central: PMC7092802].

3. Wang C, Horby PW, Hayden FG, Gao GF. A novel coronavirus outbreak of global health concern. Lancet. 2020;395(10223):470-3. doi: 10.1016/S0140-6736(20)30185-9. [PubMed: 31986257]. [PubMed Central: PMC7135038].

4. World Health Organization. WHO announces COVID-19 outbreak a pandemic. Geneva, Switzerland: World Health Organization; 2020 [cited 2021]. Available from: https://www.euro.who.int/en/healthtopics/health-emergencies/coronavirus-covid-19/news/news/ 2020/3/who-announces-covid-19-outbreak-a-pandemic.
5. World Health Organization. WHO Coronavirus (COVID-19) Dashboard. Geneva, Switzerland: World Health Organization; 2021, [cited 2021]. Available from: https://covid19.who.int/.

6. Honarvar B, Lankarani KB, Kharmandar A, Shaygani F, Zahedroozgar M, Rahmanian Haghighi MR, et al. Knowledge, attitudes, risk perceptions, and practices of adults toward COVID-19: a population and field-based study from Iran. Int J Public Health. 2020;65(6):731-9. doi: 10.1007/s00038-020-01406-2. [PubMed: 32583009]. [PubMed Central: PMC7311321]

7. Wu Z, McGoogan JM. Characteristics of and Important Lessons From the Coronavirus Disease 2019 (COVID-19) Outbreak in China: Summary of a Report of 72314 Cases From the Chinese Center for Disease Control and Prevention. JAMA. 2020;323(13):1239-42. doi: 10.1001/jama.2020.2648. [PubMed: 32091533].

8. Adhikari SP, Meng S, Wu YJ, Mao YP, Ye RX, Wang QZ, et al. Epidemiology, causes, clinical manifestation and diagnosis, prevention and control of coronavirus disease (COVID-19) during the early outbreak period: a scoping review. Infect Dis Poverty. 2020;9(1):29. doi: 10.1186/s40249-020-00646-x. [PubMed: 32183901]. [PubMed Central: PMC7079521]

9. National Center for Immunization and Respiratory Diseases. COVID-19 Overview and Infection Prevention and Control Priorities in non-U.S. Healthcare Settings. Georgia, USA: Centers for Disease Control and Prevention; 2021, [cited 2021]. Available from: https://www.cdc.gov/coronavirus/2019-ncov/hcp/nonus-settings/overview/index.html\#transmission.

10. Guo YR, Cao QD, Hong ZS, Tan YY, Chen SD, Jin HJ, et al. The origin, transmission and clinical therapies on coronavirus disease 2019 (COVID-19) outbreak-an update on the status. Mil Med Res. 2020;7(1):11. doi: 10.1186/s40779-020-00240-0. [PubMed: 32169119]. [PubMed Central: PMC7068984].

11. Huynh G, Nguyen TH, Tran V, Vo K, Vo V, Pham L. Knowledge and attitude toward COVID-19 among healthcare workers at District 2 Hospital, Ho Chi Minh City.Asian PacJTrop Med.2020;13(6). doi:10.4103/19957645.280396

12. Khan Z, Muhammad K, Ahmed A, Rahman H. Coronavirus outbreaks: prevention and management recommendations. Drugs Ther Perspect. 2020:1-3. doi: 10.1007/s40267-020-00717-x. [PubMed: 32218651]. [PubMed Central: PMC7095077].

13. World Health Organization. A guide to developing knowledge, attitude and practice surveys. Geneva, Switzerland: World Health Organization; 2008.

14. Ahdab SA. Knowledge, Attitudes and Practices (KAP) towards pandemic COVID-19 among Syrians. ResearchSquare. 2020;Preprint. doi: 10.21203/rs.3.rs-27859/v2.

15. ul Haq N, Malik Z, Nasim A, Riaz S, Mohammad G, Azhar S. Knowledge, Attitude and Practice Towards Hepatitis B Among Medical College Students of Quetta, Pakistan. Value Health. 2016;19(7). doi: 10.1016/j.jval.2016.08.546.

16. Papagiannis D, Malli F, Raptis DG, Papathanasiou IV, Fradelos EC, Daniil Z, et al. Assessment of Knowledge, Attitudes, and Practices towards New Coronavirus (SARS-CoV-2) of Health Care Professionals in Greece before the Outbreak Period. Int I Environ Res Public Health. 2020;17(14):4925. doi: 10.3390/ijerph17144925. [PubMed: 32650614]. [PubMed Central: PMC7400230].

17. Abbag HF, El-Mekki AA, Al Bshabshe AAA, Mahfouz AA, Al-Dosry AA, Mirdad RT, et al. Knowledge and attitude towards the Middle East respiratory syndrome coronavirus among healthcare personnel in the southern region of Saudi Arabia. J Infect Public Health. 2018;11(5):720-2. doi: 10.1016/j.jiph.2018.02.001. [PubMed: 29525570]. [PubMed Central: PMC7102736]

18. Al-Hazmi A, Gosadi I, Somily A, Alsubaie S, Bin Saeed A. Knowledge, attitude and practice of secondary schools and university students toward Middle East Respiratory Syndrome epidemic in Saudi Arabia: A cross-sectional study. Saudi J Biol Sci. 2018;25(3):572-7. doi: 10.1016/j.sjbs.2016.01.032. [PubMed: 29686521]. [PubMed Central: PMC5910645]. 
19. Choi JS, Kim KM. Infection-control knowledge, attitude, practice, and risk perception of occupational exposure to Zika virus among nursing students in Korea: A cross-sectional survey. J Infect Public Health. 2018;11(6):840-4. doi: 10.1016/j.jiph.2018.07.002. [PubMed: 30049612]. [PubMed Central: PMC7102775].

20. Vartti AM, Oenema A, Schreck M, Uutela A, de Zwart O, Brug J, et al. SARS knowledge, perceptions, and behaviors: a comparison between Finns and the Dutch during the SARS outbreak in 2003. Int J Behav Med. 2009;16(1):41-8. doi: 10.1007/s12529-008-9004-6. [PubMed: 19184625]. [PubMed Central: PMC7091200].

21. Alkot M, Albouq M, Shakuri M, Subahi M. Knowledge, attitude, and practice toward MERS-CoV among primary health-care workers in Makkah Al-Mukarramah: an intervention study. Int J Med Sci Public Health. 2016;5(5). doi: 10.5455/ijmsph.2016.24012016345.

22. Almutairi KM, Al Helih EM, Moussa M, Boshaiqah AE, Saleh Alajilan A, Vinluan JM, et al. Awareness, Attitudes, and Practices Related to Coronavirus Pandemic Among Public in Saudi Arabia. Fam Community Health. 2015;38(4):332-40. doi:10.1097/FCH.0000000000000082. [PubMed: 26291193].

23. Abdelhafiz AS, Mohammed Z, Ibrahim ME, Ziady HH, Alorabi M, Ayyad M, et al. Knowledge, Perceptions, and Attitude of Egyptians Towards the Novel Coronavirus Disease (COVID-19). J Community Health.2020;45(5):881-90. doi:10.1007/s10900-020-00827-7. [PubMed: 32318986]. [PubMed Central: PMC7173684].

24. Azlan AA, Hamzah MR, Sern TJ, Ayub SH, Mohamad E. Public knowledge, attitudes and practices towards COVID-19: A crosssectional study in Malaysia. PLoS One. 2020;15(5). e0233668. doi: 10.1371/journal.pone.0233668. [PubMed: 32437434]. [PubMed Central: PMC7241824].

25. Clements JM. Knowledge and Behaviors Toward COVID-19 Among US Residents During the Early Days of the Pandemic: Cross-Sectional Online Questionnaire. JMIR Public Health Surveill. 2020;6(2). e19161. doi: 10.2196/19161. [PubMed: 32369759]. [PubMed Central: PMC7212816].

26. Reuben RC, Danladi MMA, Saleh DA, Ejembi PE. Knowledge, Attitudes and Practices Towards COVID-19: An Epidemiological Survey in North-Central Nigeria. J Community Health. 2021;46(3):457-70. doi: 10.1007/s10900-020-00881-1. [PubMed: 32638198]. [PubMed Central: PMC7338341].
27. Zhong BL, Luo W, Li HM, Zhang QQ, Liu XG, Li WT, et al. Knowledge, attitudes, and practices towards COVID-19 among Chinese residents during the rapid rise period of the COVID-19 outbreak: a quick online cross-sectional survey. Int J Biol Sci. 2020;16(10):174552. doi: 10.7150/ijbs.45221. [PubMed: 32226294]. [PubMed Central: PMC7098034]

28. Chen Y, Jin YL, Zhu LJ, Fang ZM, Wu N, Du MX, et al. [The network investigation on knowledge, attitude and practice about Novel coronavirus pneumonia of the residents in Anhui Province] Zhonghua Yu Fang Yi Xue Za Zhi. 2020;54(0). Chinese. E004. doi: 10.3760/cma.j.issn.0253-9624.2020.0004. [PubMed: 32064854].

29. Saqlain M, Munir MM, Rehman SU, Gulzar A, Naz S, Ahmed Z, et al Knowledge, attitude, practice and perceived barriers among healthcare workers regarding COVID-19: a cross-sectional survey from Pakistan. J Hosp Infect. 2020;105(3):419-23. doi: 10.1016/j.jhin.2020.05.007. [PubMed: 32437822]. [PubMed Central: PMC7211584].

30. Lau LL, Hung N, Go DJ, Ferma J, Choi M, Dodd W, et al. Knowledge, attitudes and practices of COVID-19 among income-poor households in the Philippines: A cross-sectional study.J Glob Health. 2020;10(1):11007. doi: 10.7189/jogh.10.011007. [PubMed: 32566169]. [PubMed Central: PMC7294392].

31. Roy D, Tripathy S, Kar SK, Sharma N, Verma SK, Kaushal V. Study of knowledge, attitude, anxiety \& perceived mental healthcare need in Indian population during COVID-19 pandemic. Asian J Psychiatr. 2020;51:102083. doi: 10.1016/j.ajp.2020.102083. [PubMed: 32283510]. [PubMed Central: PMC7139237].

32. Ajzen I, Fishbein M. The influence of attitudes on behavior. In: Albarracín D, Johnson BT, Zanna MP, editors. The handbook of attitudes: Lawrence Erlbaum. East Sussex, UK: Psychology Press; 2005.

33. Fisher WA, Fisher JD, Rye BJ. Understanding and promoting AIDS preventive behavior: insights from the theory of reasoned action. Health Psychol.1995;14(3):255-64. doi: 10.1037||0278-6133.14.3.255. [PubMed: 7641667].

34. Li LQ, Huang T, Wang YQ, Wang ZP, Liang Y, Huang TB, et al. COVID-19 patients' clinical characteristics, discharge rate, and fatality rate of meta-analysis. J Med Virol. 2020;92(6):577-83. doi: 10.1002/jmv.25757. [PubMed: 32162702]. [PubMed Central: PMC7228329]. 
Table 2. Knowledge of Studied Participants Regarding COVID-19

\begin{tabular}{|c|c|}
\hline Knowledge of Participants Regarding COVID-19 & No. $(\%)$ \\
\hline \multicolumn{2}{|l|}{ Do you think that the COVID-19 disease is contagious? } \\
\hline Yes & $667(97.20)$ \\
\hline No & $5(0.70)$ \\
\hline I do not know & $14(2)$ \\
\hline \multicolumn{2}{|l|}{ Is there a treatment for the disease? } \\
\hline Yes & $123(17.90)$ \\
\hline No & $425(62)$ \\
\hline I do not know & $138(20.10)$ \\
\hline \multicolumn{2}{|c|}{ Do you think that separating suspected people from others is essential? } \\
\hline Yes & $676(98.30)$ \\
\hline No & $5(0.70)$ \\
\hline I do not know & $7(1)$ \\
\hline \multicolumn{2}{|c|}{ Do you think that a fast diagnosis of the disease can help excel the treatment? } \\
\hline Yes & $616(89.50)$ \\
\hline No & $29(4.20)$ \\
\hline I do not know & $43(6.30)$ \\
\hline \multicolumn{2}{|l|}{ Is there a vaccine available for the disease? } \\
\hline Yes & $30(4.40)$ \\
\hline No & $525(76.50)$ \\
\hline I do not know & $131(19.10)$ \\
\hline \multicolumn{2}{|l|}{ Can the seasonal flu shot help with the COVID-19 disease? } \\
\hline Yes & $9(1.30)$ \\
\hline No & $467(67.80)$ \\
\hline I do not know & $213(30.90)$ \\
\hline \multicolumn{2}{|c|}{ Do you think that health education can help with not contracting the disease? } \\
\hline Yes & $654(94.90)$ \\
\hline No & $13(1.90)$ \\
\hline I do not know & $22(3.20)$ \\
\hline \multicolumn{2}{|l|}{ Can this virus stay alive for several days on surfaces? } \\
\hline Yes & $628(91.30)$ \\
\hline No & $30(4.40)$ \\
\hline I do not know & $30(4.40)$ \\
\hline \multicolumn{2}{|c|}{ How many people do you think somebody with the disease can make sick with every contact? } \\
\hline Less than two people & $10(1.50)$ \\
\hline 2-3 People & $105(15.20)$ \\
\hline More than 3 people & $491(71.30)$ \\
\hline I do not know & $83(12)$ \\
\hline \multicolumn{2}{|l|}{ Which of the following is the cause of the disease? } \\
\hline Bacterium & $3(0.4)$ \\
\hline Virus & $586(85.10)$ \\
\hline Fungus & $0(0)$ \\
\hline Immune system dysfunction & $72(10.40)$ \\
\hline I do not know & $28(4.10)$ \\
\hline \multicolumn{2}{|c|}{ Which of the following is how the disease can be transmitted? } \\
\hline Direct transmission through coughing & $591(86)$ \\
\hline Touching virus-contaminated surfaces & $635(92.40)$ \\
\hline Direct contact with somebody with the disease & $604(87.90)$ \\
\hline I do not know & $9(1.30)$ \\
\hline
\end{tabular}

Which of the following are the signs and symptoms of the disease? 
Fever or headache

Dry cough

Respiratory distress

$647(94.20)$

Sore throat

458 (66.70)

Fatigue and malaise

$427(62.20)$

I do not know

$8(1.20)$

How many days would it take for the sign and symptoms of disease to appear in someone with the disease?

Fewer than 2 days after contraction

$11(1.60)$

2-5 after contraction

2-14 after contraction

44 (6.40)

I do not know

$601(87.50)$

$31(4.50)$

What are the risk factors for contracting the disease?

Higher age

$586(82.70)$

People with cancer, diabetes, and respiratory diseases

$615(89.50)$

Traveling to places where the disease is prevalent

$514(74.80)$

Pregnant women

$354(51.50)$

I do not know

$9(1.30)$

What are the ways of prevention of the COVID-19 disease?

Washing hands with soap and water

$670(97.50)$

Refraining from touching the mouth, nose, and eyes

$622(90.50)$

Having no contact with suspected people and people who have contracted the disease

$624(90.80)$

Use of masks by suspected people and those with the disease

$599(87.20)$

I do not know 
Table 3. Attitude and Practice of Studied Participants Regarding COVID-19

\begin{tabular}{|c|c|}
\hline Attitude of Participants Regarding COVID-19 & No. (\%) \\
\hline \multicolumn{2}{|l|}{ Do you think that this disease is dangerous? } \\
\hline Yes & $599(87.20)$ \\
\hline No & $43(6.30)$ \\
\hline Not sure & $45(6.60)$ \\
\hline \multicolumn{2}{|l|}{ Do you feel at risk for contracting the disease? } \\
\hline Yes & $391(56.90)$ \\
\hline No & $138(20.10)$ \\
\hline Not sure & $158(23)$ \\
\hline \multicolumn{2}{|c|}{ Are you worried about any of your family members contracting the disease? } \\
\hline Yes & $586(85.30)$ \\
\hline No & $52(7.60)$ \\
\hline Not sure & $49(7.10)$ \\
\hline Yes & $561(81.70)$ \\
\hline No & $48(7)$ \\
\hline Not sure & $78(11.40)$ \\
\hline \multicolumn{2}{|c|}{ Are you afraid of going into crowded places because of the disease? } \\
\hline Yes & $600(87.30)$ \\
\hline No & $62(9)$ \\
\hline Not sure & $25(3.60)$ \\
\hline \multicolumn{2}{|c|}{ Can we prevent the disease by taking prudent measures? } \\
\hline Yes & $612(89.10)$ \\
\hline No & $11(1.60)$ \\
\hline Not sure & $64(9.30)$ \\
\hline \multicolumn{2}{|c|}{ Should we refer to a doctor when signs and symptoms of the disease appear in us? } \\
\hline Yes & $519(75.50)$ \\
\hline Not sure & $52(7.60)$ \\
\hline \multicolumn{2}{|c|}{ Should we stop doing daily activities if we have the signs and symptoms of the disease? } \\
\hline Yes & $500(72.80)$ \\
\hline No & $123(17.90)$ \\
\hline Not sure & $64(9.30)$ \\
\hline \multicolumn{2}{|c|}{ Is it necessary to have less contact with people with the disease to control it? } \\
\hline Yes & $642(93.40)$ \\
\hline No & $17(2.50)$ \\
\hline Not sure & $28(4.10)$ \\
\hline \multicolumn{2}{|c|}{ Should there be a city to city transportation limits made by the government? } \\
\hline Yes & $661(96.20)$ \\
\hline No & $10(1.50)$ \\
\hline Not sure & $16(2.30)$ \\
\hline \multicolumn{2}{|c|}{ Are preventive measures taken by people enough to prevent the disease? } \\
\hline Yes & $184(26.80)$ \\
\hline No & $338(49.20)$ \\
\hline Not sure & $165(24)$ \\
\hline \multicolumn{2}{|c|}{ Can the government organizations alone control the epidemic? } \\
\hline Yes & $25(3.60)$ \\
\hline No & $617(89.80)$ \\
\hline Not sure & $45(6.6)$ \\
\hline
\end{tabular}

Which of the Following Preventive Actions Do You Practice to Prevent the Contraction of the Disease? 


\begin{tabular}{|c|c|}
\hline \multicolumn{2}{|c|}{ I usually wash my hands with soap and water } \\
\hline No & $36(5.20)$ \\
\hline Yes & $651(94.80)$ \\
\hline \multicolumn{2}{|c|}{ I refrain from touching my nose, mouth, and eyes } \\
\hline No & $99(14.40)$ \\
\hline Yes & $588(85.60)$ \\
\hline \multicolumn{2}{|c|}{ I throw the mask or the paper tissue in the trash can after use } \\
\hline No & $159(23.10)$ \\
\hline Yes & $528(76.90)$ \\
\hline \multicolumn{2}{|c|}{ I use a mask to cover my nose and mouth in crowded places } \\
\hline No & $140(20.40)$ \\
\hline Yes & $547(79.60)$ \\
\hline \multicolumn{2}{|c|}{ I cover my nose and mouth with a paper tissue when I sneeze, or I sneeze into my elbow } \\
\hline No & $109(15.90)$ \\
\hline Yes & $578(84.10)$ \\
\hline \multicolumn{2}{|c|}{ As recommended by the Ministry of Health, I stay home to cut the chain of disease transmission } \\
\hline No & $91(13.20)$ \\
\hline Yes & $596(86.80)$ \\
\hline \multicolumn{2}{|c|}{ I will not travel in order not to catch the disease } \\
\hline No & $76(11.10)$ \\
\hline Yes & $611(88.90)$ \\
\hline \multicolumn{2}{|c|}{ None of the above } \\
\hline No & $683(99.30)$ \\
\hline Yes & $5(0.7)$ \\
\hline
\end{tabular}

